\title{
Assessing Australian Attitudes to Japan in the Early Twentieth Century - A New Approach ${ }^{1}$
}

\author{
Ben McInnes \\ The University of New England
}

After living in Japan for almost seventeen years, and being constantly intrigued by the attitudes of the Japanese to Australia, upon my return I was naturally interested to learn about Australian attitudes to Japan. The paucity of news concerning Japan in the press suggested that it was not of major interest to the Australian public, and one tends to presume that, wartime apart, this had always been the case. An interest in Australian history fostered by prolonged absence was partly satisfied by undertaking volunteer work for the National Trust of Australia, at their property 'Saumarez Homestead', located in the rural city of Armidale, New South Wales, where I had taken up residence. 'Saumarez' is a large Victorian-Edwardian pastoral property, purchased by Francis John White in 1874. White and his wife Margaret raised their five daughters and two sons on the property, and became wealthy and socially important people in the township. While this may seem irrelevant to my experience in Japan, I was amazed to discover that Mary White, the eldest daughter of the 'Saumarez' family, had indeed travelled to Japan in 1903, and I soon learned that quite a number of other local people had done the same in the period between Federation and World War I. That residents of what was a rather isolated community in country Australia had gone to the trouble and expense to travel such a long way, taking steamships up the Queensland coast, stopping over in Manila and Hong Kong, and taking over six weeks to reach 'the land of topsy-turvydom', as Japan was referred to in the local press on one occasion, suggested that an investigation of attitudes to Japan in this part of Australia in the early years of the twentieth century might provide some significant data on the development of the Australia-Japan relationship. ${ }^{2}$

Several extraordinary events occurred in the Pacific Region in the first decade of the twentieth century - events which, while not directly involving Australia, are reputed to have had a profound impact on Australian attitudes towards Japan. Previous studies have concluded that the Russo-Japanese War of 1904-05 had an enormously positive effect on Australian perceptions of Japan. Australian public opinion was overwhelmingly in favour of the Japanese, ${ }^{3}$ who were seen as being 'engaged in a heroic resistance to

\footnotetext{
${ }^{1}$ This article is based upon research undertaken in the School of Languages, Cultures and Linguistics, University of New England, under the supervision of Associate Professor Hugh de Ferranti. The author wishes to express his sincere thanks both to Professor de Ferranti and to Dr. Frank Bongiorno of the School of Classics, History and Religion, for several very useful discussions of the material in this work. ${ }^{2}$ The rural press reviewed for this research also revealed a number of articles concerning an event now largely forgotten in Australia, and even in Japan - the first Japanese Antarctic expedition of 1910 to 1912. This expedition, headed by Lieutenant Nobu Shirase, arrived in Sydney Harbour in May, 1911, enroute to a second attempt on the Antarctic, and was widely reported in the press. Preliminary investigations disclosed a number of facts that led me to suspect that an important figure not only in Japanese history, but also in the history of Antarctic exploration, had been unfairly neglected in recent research. As a result, Shirase's expedition has now become the topic of my doctoral research.

${ }^{3}$ See for example, Hayne, 'The impact of the Battle of Tsushima', p. 274; Sandra Tweedie, Trading Partners, p. 34.
} 
Russian encroachment.4 That the Japanese Consul in Sydney, as well as Burns, Philp, and Company - agents of the Japan Mail Steamship Company (Nippon Yusen Kaisha, or, more commonly, N.Y.K.) - found it necessary to discourage Australian would-be volunteers with the announcement that despite the large number of applications ... being daily received ... there is no possible chance of any officers or men being allowed to join the Japanese forces other than Japanese, illustrates the extent to which Australian sympathies lay with Japan. ${ }^{5}$ The warm welcome extended to the Training Japanese Naval Squadron upon its visit to Australian waters in 1906 bears ample witness to the nature of Australian sentiments immediately following the battle. ${ }^{6}$

From this point on, however, the literature has claimed unanimously that Australian attitudes towards Japan rapidly became negative. A number of explanations have been advanced for this shift. D.C.S. Sissons ${ }^{7}$ proposed the Russo-Japanese War as the source of both positive and negative sentiments towards Japan, with the negative feelings not assuming predominance until some time after the war, although he gave no convincing argument as to why this 'delayed reaction' should have occurred. A.T. Yarwood ${ }^{8}$ suggested that the cause of the sudden escalation in anti-Japanese attitudes in Australia was a result of the fear aroused by the threat of war between Japan and the United States in 1906 and into 1907, over the so-called California School Board Crisis. Yarwood claimed that Australians felt that the racial tensions behind the conflict were ominous for an Australia that had only recently introduced an Alien Restriction Act, a view with which both Takeda ${ }^{9}$ and Walker ${ }^{10}$ concurred. While agreeing with Yarwood's 'racial' explanation of a reportedly Australia-wide anti-Japanese mood, Neville Meaney ${ }^{11}$ added depth to the argument by including Britain's withdrawal of naval forces from the Pacific, rumours of a collapse of the Anglo-Japanese Alliance, and the Japanese invasion of Korea in 1910-11 as all contributing to increasingly negative attitudes towards Japan.

It is significant, however, that while all of these sources used data from the contemporary press extensively, it was drawn almost without exception from the press of the capital cities. Thus, although studies of the attitudes of Australians towards Japan in the late nineteenth and early twentieth centuries have implicitly accepted the premise that items appearing in the press form a useful tool for determining contemporary Australian attitudes, researchers have then also made the presumption that attitudes throughout Australia were essentially homogeneous. The unacknowledged premise has been that the results of investigations into the attitudes of city-dwelling Australians, as determined from the metropolitan press, could be extrapolated across the entire population to arrive at an Australian attitude towards Japan.

\footnotetext{
${ }^{4}$ Yarwood, Asian Migration to Australia, p. 92.

${ }^{5}$ Sydney Morning Herald, 27 February, 1904.

${ }^{6}$ See, for example, David Walker, Anxious Nation, pp. 85-97.

${ }^{7}$ Sissons, 'Attitudes to Japan and defence 1890-1923'.

${ }^{8}$ Yarwood, op. cit.

${ }^{9}$ Takeda, 'Australia-Japan relations in the era of the Anglo-Japanese Alliance, 1896-1911'.

${ }^{10}$ Walker, op. cit.

${ }^{11}$ Meaney, The Search for Security in the Pacific.
} 
One aim of the study presented in summary here was to test the validity of this presumption that the press of the capital cities provides an accurate indication of attitudes towards Japan in all sectors of the population, including rural-dwellers, in the period 1906 to 1914. Such a 'test' was considered important because the population group across which the extrapolation has been made - the rural population - constituted a far greater portion of the total population of Australia in the period under investigation than it does today. For example, in 1906, 48.5 per cent of the total population lived on rural properties or in towns of less than three thousand people, while only 34 per cent lived in the four cities of over 100,000 people. In contrast, by 1996 only 18 per cent lived in rural areas and almost 63 per cent lived in cities of over 100,000. Similarly, although over one-third of Australians were directly engaged in primary production in 1906, only approximately five per cent were engaged in this industry in $1996 .{ }^{12}$ A division in country-city attitudes over a number of issues, including the administration of the legal system, transport, labour distribution, and government spending, was more than evident in the heated debate surrounding the decentralisation issue, in which the rural electorates struggled to retain political power against the growing might of Sydney. Whether this division was paralleled in other spheres, such as the stance taken on international matters, remains unaddressed. ${ }^{13}$ It is clear, however, that due consideration of rural attitudes is vital to the accuracy and validity of any statement of Australian attitudes in the early years of the twentieth century.

It must be emphasised that previous research in general has used not only press data, but also that to be found in a number of other sources, such as the Commonwealth Parliamentary Debates, the writings and correspondence of politicians and other prominent persons, and defence force documents. It is not the intention of this paper to suggest that these sources are not an invaluable resource for investigations into Australian attitudes towards Japan. However, as the city press has been used consistently as one of the more important tools in such investigations, it is undeniably important that the validity of this tool as an indicator of Australia-wide attitudes be tested.

As in previous research, it was an acknowledged assumption of this study that a survey of press articles dealing with Japan during the era between the Russo-Japanese and Great wars would provide evidence of the attitudes of Australians at that time. While it could be argued that editorials might be attempting to inculcate certain attitudes in the readership, rather than reflecting already-held viewpoints, this was not felt to be an obstacle to the research. Although an individual editor might promote a point of view opposed to the generally held opinions of that newspaper's readership, the tendency of data collected from that newspaper to prejudice outcomes would be largely counteracted by the use of data from several newspapers and journals, and from not only editorials,

\footnotetext{
${ }^{12}$ Australian Bureau of Statistics, Australian Social Trends 2000, Population - Population characteristics: $20^{\text {th }}$ century: beginning and end, $<$ http://www.abs.gov.au >, accessed 26 August, 2005.

${ }^{13}$ Decentralisation was addressed in much of the rural press in the pre-Great War era; of the New England press surveyed, the Tenterfield Star in particular carried a number of articles on the subject, including on 2, 9, 19, 23 and 26 July, 1913. In the last of these articles, Inverell is cited as the starting-point of the movement.
} 
but also the range of other items appearing in the press (including news reports, readers' letters, trade and business reports, educational columns, and entertainment items).

It could be argued that the statements of politicians, for example, are a more accurate indicator of public opinion than the press, in that they would be unlikely to depart dramatically from what they understood to be mainstream public opinion. However, although political leaders are likely to 'trim their sails' to suit the mood of the voters at election times, it is clear that at other times this is not necessarily the case. In any event, by the early years of the twentieth century, Australian federal politicians often voiced extremely diverse opinions on a number of issues. Thus, basing an assessment of the attitudes of the public on the statements of any one politician alone, or even on the opinions expressed by a small group of politicians, would be fraught with dangers equally as severe as relying solely on the press.

In any case, although it is recognised that a more extensive study of the question of attitudes towards Japan would need to incorporate data from a variety of sources, the purpose of this study was not to arrive at a definitive assessment of Australian attitudes, but rather to test the validity of the presumption made in previous research that the rural press would simply echo the opinions of the capital city press, and could therefore justifiably be ignored.

A second and no less important goal of this research was to 'trial' a new methodological approach in this field, namely, the incorporation of quantitative analysis into what has been traditionally an area subject to purely qualitative methods. It should be noted here that this form of empirical research has not to this writer's knowledge been undertaken previously in a study of Australian attitudes towards Japan in the pre-World War I era. Although earlier research has discussed the general 'tone' of reports in, for example, the Sydney Morning Herald of a certain year as being positive or negative towards Japan, no actual records of the frequency with which items about Japan appeared, nor of the relative proportions of different types of items appearing in that year, have been presented. Clearly, arguments could be advanced as to the advantages or disadvantages of qualitative over quantitative methods in historical research, although a discussion of this topic is beyond the range of this paper. However, it would seem that a purely qualitative approach to this research area, where enormous amounts of data are available, serves only to expose the researcher to claims of bias; the plenitude of data means that numerous examples can be found to support nearly any argument put forward. On the other hand, a purely quantitative methodology, merely tabulating frequencies of publication of the various types of item, fails to take into account the relative weight being placed on items of any one kind by the press of the day; a passing reference to the trade relationship, for example, would be granted the same importance as a full-page article reporting the imminent threat of Japanese invasion. Although the dangers involved in combining qualitative and quantitative research were fully appreciated, it was considered that just such a combination of methods would shed new 
light on the questions addressed in this study, and might foster a deeper understanding of the issues involved. Hence, although a quantitative analysis of the data was undertaken, the output of that process was then examined qualitatively, in an attempt to avoid the weaknesses and exploit the advantages of both methodologies.

Three periods were selected as covering critical points in the interval between the Russo-Japanese War and the upheavals of the Great War. In particular, the reportedly anti-Japanese years in Australia of the California Schools Board Crisis, the intervening period of what has been labelled the era of Australian 'Crisis Fever', and the months immediately prior to Japan's entering into the conflicts of World War I, were chosen as representing periods when, according to the literature, negative attitudes towards Japan in Australia were rampant.

The New England Region of northern New South Wales was chosen as the subject of an in-depth case study. This region was selected not only because of evidence of considerable numbers of individuals from this region having travelled to Japan and of their having personal interest in that country, but also for the fact that New England had a flourishing press at the time, making it a fertile source of data. The availability of contemporary local newspapers, for example, in the Dixson Library of the University of New England, was, of course, an important consideration in the undertaking of this study.

Nine New England newspapers were surveyed, as well as two major journals. ${ }^{14}$ Although published in Sydney, the journals were included not only because of their clearly intended rural readership, but also because evidence exists that they were widely read in the New England region during the period covered by this study. All editions of the source materials were scanned for all references to Japan and the Japanese people. These items were briefly summarised and recorded by date and source.

Data items were assigned to one of four groups: those items portraying, or tending to create, a positive attitude towards Japan; those portraying a negative view; those which were neutral; and those which tended to exoticise Japan, rather than reporting events or facts.

The second phase of analysis involved the counting of occurrences of items in each group, and tabulation of results. It was recognised early in the study that the assignment of data to one of the four categories did not always present the researcher with obvious, objective choices. In the interests of reducing researcher bias to a minimum, a number of procedures were established in advance to assist in the allocation of items to one of the four categories on the basis of other features of the item itself, rather than leaving

\footnotetext{
${ }^{14}$ The newspapers were the Armidale Argus, Chronicle and Express, the Bingara Telegraph, the Glen Innes Examiner, the Tenterfield Star, the Uralla Times, the Walcha News, and the Warialda Standard. The journals were the Pastoralists' Review, and the Town \& Country Journal.
} 
the decision to the researcher in each case.

Following quantitative analysis, a detailed qualitative investigation of items categorised into the four groups was undertaken, to determine the topics or news events around which the items in each category tended to cluster. By then combining these two sets of data, it was possible to discover whether the rural press was portraying an attitude towards Japan similar to that reported in the literature for the capital cities, or whether a different view was evident.

A summary of the results of the quantitative analysis is presented in Tables 1 and 2, below:

Table 1 Totals of item types for all press surveyed by year groupings

\begin{tabular}{|c|c|c|c|c|c|c|c|c|c|c|c|c|}
\hline \multicolumn{3}{|c|}{$1906-07$} & \multicolumn{3}{c|}{$1910-11$} & \multicolumn{3}{c|}{$1913-14$} & Total \\
\hline Positive & Negative & Neutral & Exotic & Positive & Negative & Neutral & Exotic & Positive & Negative & Neutral & Exotic & \\
\hline 195 & 69 & 252 & 64 & 101 & 37 & 121 & 29 & 138 & 29 & 101 & 23 & 1159 \\
\hline \multicolumn{3}{|c|}{ Total 580} & \multicolumn{3}{c|}{ Total 288 } & \multicolumn{3}{c|}{ Total 291 } & \\
\hline
\end{tabular}

Table 2 Totals of item types for entire survey

\begin{tabular}{|l|c|c|}
\hline Item Type & Number & $\begin{array}{c}\text { Percentage of total } \\
\text { (rounded to nearest } \\
\text { whole number) }\end{array}$ \\
\hline Positive & 434 & 37 \\
Negative & 135 & 12 \\
Neutral & 474 & 41 \\
Exoticising & 116 & 10 \\
\hline TOTAL & 1159 & 100 \\
\hline
\end{tabular}

Previous research utilising data from the Australian capital city press has claimed that, although positive attitudes prevailed in Australia up to and including the years of the Russo-Japanese War, Australian attitudes towards Japan became increasingly negative following the U.S.-Japanese tensions of 1906-07. Spurred on by the annexation of Korea in 1910-11 and the uncertainties of the Anglo-Japanese Alliance, Australian fears reportedly continued to grow, such that Australian attitudes towards Japan have been generally portrayed as undergoing a rapid deterioration between 1906 and the Great War. 
A test of the validity of the presumption that the press of the capital cities alone could provide an accurate indication of attitudes towards Japan of all sectors of the population in this period was considered important because the population group across which the extrapolation was made - the rural population - constituted close to half of the total population of Australia at the time. Thus, any diversity in attitudes made evident from such an investigation would have profound implications for the validity of the claims of previous studies.

Analysis of the data revealed that, in comparison with items suggesting negative attitudes towards Japan (approximately 12 per cent), a substantially greater number of items giving a positive image of Japan were published in the period surveyed (approximately 37 per cent). This fact alone raises serious questions as to the applicability of conclusions based on analysis of the city press to the New England region at least, if not to all rural areas. In-depth qualitative analysis of the data suggested that, in particular, the trade relationship already in place between the nations had tended to create a far more positive attitude towards Japan in the New England region than has been reported in the literature. Indeed, the data revealed that, with regard to the wool trade, the rural press assumed a competitive stance towards England for access to the Japanese market, and expressed pride in Japan's high regard for Australian wool. Other Positive items in the press suggested not only a level of admiration for the Japanese, but also a willingness to accept a wide variety of Japanese influences into rural Australian leisure and aesthetic interests in this period.

In addition to the large number of Positive items identified in the survey, an even greater number of Neutral items were also discovered. For the purposes of this study, Neutral items were defined as those items which were (a) a purely 'factual' report of news or other events, which (b) contained no statement of opinion or discussion of implications for Australia which would allow the item to be counted in any other category, and (c), which were not clearly reporting events which would be perceived as having a direct and negative or positive impact on Australia. The presence of Neutral items has not been identified in the city press by previous research on attitudes to Japan. If a proportionally large body of data did indeed exist in the city press, the failure to acknowledge this fact is regrettable for two reasons:

1. It might have resulted in a serious underestimation of the sophistication of the Australian general public regarding Japan in the pre-World War I era. Walker has made the intriguing claim that, 'One of the remarkable features of Australian history is the periodic rediscovery of our proximity to Asia. ${ }^{15}$ It seems possible that Australians in the early years of the twentieth century were well aware of their proximity to Japan, but that postWorld War II researchers, themselves influenced by a legacy of alienation and hostility arising from their wartime experiences, were unappreciative or dismissive of the closer

${ }^{15}$ Walker, op. cit., p. 1. 
relationship with Japan enjoyed by an earlier generation. This conjecture invites investigation beyond the scope of this paper.

2. If the ratio of Neutral items to Negative items in the city press was comparable to the ratio identified in this study of the rural press, where approximately 3.5 times as many Neutral items appeared as Negative items, failure to note this fact may have significantly biased conclusions regarding the predominant 'tone' of Australian attitudes towards Japan.

In this study, it was observed that Neutral items were frequently concerned with events portrayed in previous research as 'triggers' to anti-Japanese sentiment in Australia. In other words, events which were treated neutrally in the New England region were among those that other studies have stated were being portrayed negatively in the city press. Based on the results of data analysis in this study, the implication is that attitudes in the New England region might not have been so easily swayed against a nation that was both a trading partner recognised as an important customer for the products of that region, and a country worthy of respect and intelligent regard in its own right.

With regard to Exoticising items, this study revealed that such items comprised only a relatively insignificant portion of all items concerning Japan published in the press in the years surveyed. This counter-intuitive discovery lent further weight to the argument that the sophistication of the Australian public regarding Japan in the pre-World War I era has been seriously underestimated by Australians of the late twentieth and early twenty-first centuries. The presumption that the press of a century ago would have been far more likely to exoticise Japan than is common today perhaps speaks more of current ideas held by Australians with regard to their own history, than of Australian attitudes towards Japan at that time.

In summary, the following observations can be made:

1. That attitudes towards Japan in the New England region of New South Wales in the period from 1906 to 1914, as represented in the press of that region, were overwhelmingly neutral or positive in terms of the attitude towards Japan portrayed.

2. That, contrary to the assumptions of previous research, Australian attitudes towards Japan were not homogeneous in the period under investigation. At least in the New England Region, attitudes in the pre-Great War era were found to differ significantly from the attitudes of city-dwellers as they have been reported in the literature.

Although this paper presents little more than the preliminary results of an initial research programme, the intriguing possibilities raised by the application of this new methodological approach to the study of what might justifiably be considered the formative years of the Australia-Japan relationship suggest the value of further investigation. Initially, it would be of great benefit to apply this same combination of quantitative and qualitative 
analyses to the press of other rural areas of Australia in the same period, to determine whether similar patterns of data emerge as those identified in the New England press. Following this, the application of this method to the city press would allow an objective comparison of rural and city press data. Of course, the collection and analysis of other sources of data concerning the attitudes of rural Australians to Japan in the pre-Great War era would advance all such research enormously.

Clearly, the field of what might be termed 'rural historical studies' is one which has been sorely neglected in studies of the Australia-Japan relationship in the nineteenth and early twentieth centuries. It is hoped that the present study might not only stimulate further investigations in this area, but also serve to foster a greater appreciation of the historical role played by rural Australians in the shaping of the relationship. In addition, the otherwise less-than-obvious balance of attitudes in the press revealed by the combination of quantitative and qualitative methods might encourage more demonstrably objective approaches to historical research in the field of Australia-Japan relations.

\section{References}

\section{A. Primary sources}

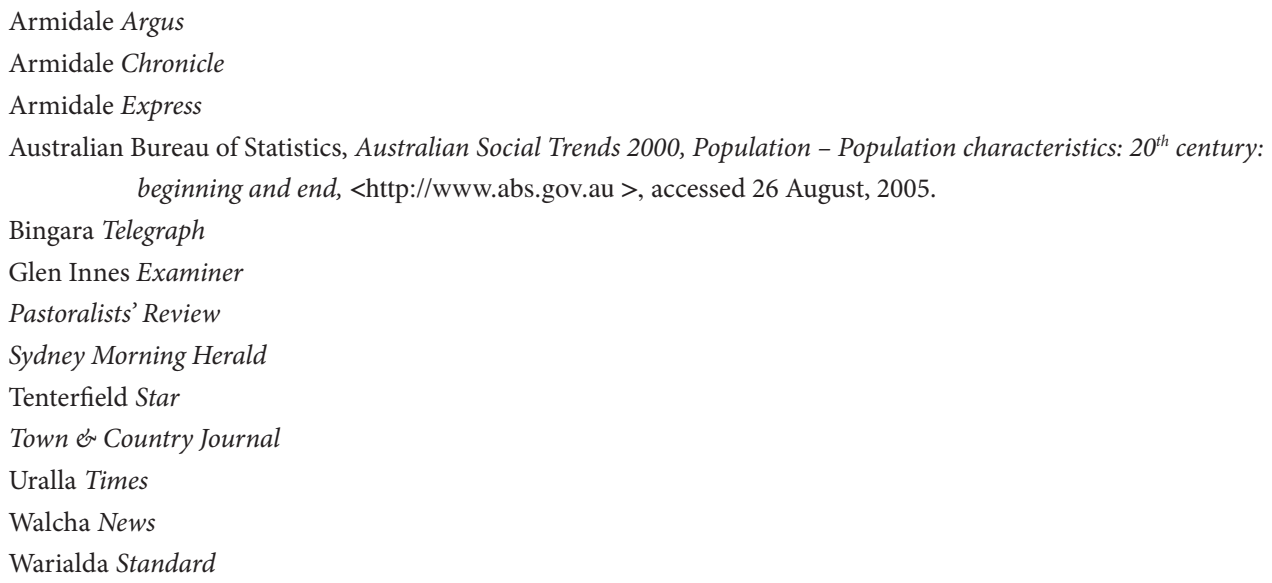

\section{B. Secondary sources}

Hayne, M.B., 'The impact of the Battle of Tsushima on Australian defence and foreign policy 1905-1909', Journal of the Royal Australian Historical Society, 72, 1987, pp. 273-287.

Meaney, N., The Search for Security in the Pacific, 1901-14 (Sydney: Sydney University Press, 1976).

Sissons, D.C.S., 'Attitudes to Japan and defence 1890-1923', Master of Arts thesis, University of Melbourne, 1956. 
New Voices

Tweedie, S., Trading Partners Australia and Asia 1790-1993 (Sydney: University of New South Wales, 1994).

Walker, D., Anxious Nation: Australia and the Rise of Asia 1850-1939 (Brisbane: University of Queensland, 1999).

Yarwood, A.T., Asian Migration to Australia: The Background to Exclusion 1896-1923 (Melbourne: Melbourne University Press, 1964). 